\title{
Papers
}

\section{Organisational downsizing, sickness absence, and mortality: 10-town prospective cohort study}

\author{
Jussi Vahtera, Mika Kivimäki, Jaana Pentti, Anne Linna, Marianna Virtanen, Pekka Virtanen, Jane E Ferrie
}

\begin{abstract}
Objective To examine whether downsizing, the reduction of personnel in organisations, is a predictor of increased sickness absence and mortality among employees.

Design Prospective cohort study over 7.5 years of employees grouped into categories on the basis of reductions of personnel in their occupation and workplace: no downsizing $(<8 \%$ reduction), minor downsizing (8-18\%), and major downsizing $(>18 \%)$.

Setting Four towns in Finland.

Participants 5909 male and 16521 female municipal employees, aged 19-62 years, who kept their jobs.

Main outcome measures Annual sickness absence rate based on employers' records before and after downsizing by employment contract; all cause and cause specific mortality obtained from the national mortality register.

Results Major downsizing was associated with an increase in sickness absence (P for trend $<0.001$ ) in permanent employees but not in temporary employees. The extent of downsizing was also associated with cardiovascular deaths $(\mathrm{P}$ for trend $<0.01$ ) but not with deaths from other causes. Cardiovascular mortality was 2.0 (95\% confidence interval 1.0 to 3.9$)$ times higher after major downsizing than after no downsizing. Splitting the follow up period into two halves showed a 5.1 (1.4 to 19.3) times increase in cardiovascular mortality for major downsizing during the first four years after downsizing. The corresponding hazard ratio was 1.4 (0.6 to 3.1) during the second half of follow up.

Conclusion Organisational downsizing may increase sickness absence and the risk of death from cardiovascular disease in employees who keep their jobs.
\end{abstract}

\section{Introduction}

Since the recessions that hit most industrialised countries during the 1990s, evidence has accumulated of health risks to the survivors of corporate downsizing. One of the first studies in the field was conducted among municipal employees of town of Raisio, Finland. The Raisio study found that the risk of health problems, as indicated by medically certified sickness absence and other indicators of health, was at least twice as great after major downsizing as after no downsizing. ${ }^{1-3}$ Half of this excess risk was attributable to an elevated level of work stress after major downsizing. ${ }^{23}$ Adverse effects on the health of survivors of downsizing have since been shown in several other studies. ${ }^{4}$ However, some evidence exists that employees in downsizing organisations may be reluctant to take leave, in effect reducing measured sickness absence through an increased likelihood of attending work while ill. ${ }^{5}$ Recent research suggests that findings may vary by employment contract, with increased sickness absence among permanent employees and increased attendance during sickness among temporary employees. ${ }^{7}$

Although further research on sickness absence is needed to improve understanding of the health effects of downsizing, a major step forward would be the assessment of hard end points such as mortality. Evidence exists that work stress can increase cardiovascular deaths, ${ }^{8-10}$ and results from studies in nonoccupational settings suggest that stressful life events may trigger fatal cardiovascular disease in the first years after the event. ${ }^{11}{ }^{12}$ If downsizing is indeed a highly stressful event, then risk of cardiovascular death among employees should increase after major downsizing. We therefore studied the association between downsizing, sickness absence, and mortality in a large cohort of permanent and temporary employees.

\section{Methods}

\section{Study context}

Between 1991 and 1996, Finland faced a severe economic decline. Unemployment rose from $6.6 \%$ in 1991 to $16.6 \%$ in 1993, the worst year of the recession. ${ }^{1}$ Economic recovery started in 1995 , but unemployment remained relatively high $(14.6 \%$ in 1996). The number of Finnish local government personnel fell by $2.7 \%$ from 1991 to 1992 , by $7.8 \%$ from 1992 to 1993, and by 2.7\% from 1993 to 1994 .

\section{Participants}

From the 10 towns participating in the Finnish 10-town study, we selected the four towns (Espoo, Turku, Vantaa, and Raisio) in which the employers' records stored on computer covered the period from 1991 to 2000 . The total working hours in the towns studied fell by $11.3 \%$ between 1991 and 1993, but only by $1.3 \%$ between 1993 and 1994. After this, the figures turned to a slight increase.

Of the 23517 full time permanent municipal employees and 4850 temporary municipal employees who had been in the service of the towns before downsizing in 1991, 5937 employees lost or left their jobs during the downsizing in 1992-3 and were excluded from the study. The participants were all the 22430 employees (5909 men and 16521 women, aged 19-62 years at study entry) who were in the service of the towns before and during the years of downsizing - that is, more than six months in both 1991 and 1993.

\section{Measurements}

The extent of downsizing (reduction in personnel) is an ecological measure that indicates the decrease in total number of person 
Table 1 Characteristics of the participants by the extent of downsizing. Values are numbers (percentages)

\begin{tabular}{|c|c|c|c|c|}
\hline & \multirow[b]{2}{*}{ All participants $(n=22430)$} & \multicolumn{3}{|c|}{ Extent of downsizing ${ }^{*}$} \\
\hline & & None $(\mathrm{n}=7915)$ & Minor $(\mathrm{n}=9700)$ & Major $(n=4787)$ \\
\hline \multicolumn{5}{|l|}{ Sex: } \\
\hline Men & $5909(26)$ & $1998(25)$ & $2970(31)$ & $(20)$ \\
\hline Women & $16521(74)$ & $5917(75)$ & $6730(69)$ & $3853(80)$ \\
\hline \multicolumn{5}{|l|}{ Age group (years): } \\
\hline $18-45$ & $14190(63)$ & $4949(63)$ & $6188(64)$ & $3028(63)$ \\
\hline $46-55$ & $6826(31)$ & $2476(31)$ & $2925(30)$ & $1423(30)$ \\
\hline$>55$ & $1414(6)$ & 490 & 587 & 336 \\
\hline \multicolumn{5}{|l|}{ Socioeconomic status: } \\
\hline Higher grade non-manual & $7923(35)$ & $4621(58)$ & $2113(22)$ & $1189(25)$ \\
\hline Lower grade non-manual & $9144(41)$ & $2622(33)$ & $4470(46)$ & $2052(43)$ \\
\hline Manual & $5335(24)$ & 672 & $3117(32)$ & $1546(32)$ \\
\hline \multicolumn{5}{|l|}{ Type of employment contract: } \\
\hline Permanent & 20330(91) & 7 102(90) & 9059(93) & $4160(87)$ \\
\hline Fixed term & $2100(9)$ & $813 \quad(10)$ & 641 & $(13)$ \\
\hline \multicolumn{5}{|l|}{ Town: } \\
\hline Raisio & $974 \quad(4)$ & $180 \quad(2)$ & $482 \quad(5)$ & (6) \\
\hline Turku & $7140(32)$ & $1677(21)$ & $3661(38)$ & $1797(38)$ \\
\hline Vantaa & $6957(31)$ & $2956(38)$ & $2141(22)$ & $1849(39)$ \\
\hline Espoo & $7359(33)$ & $3102(39)$ & $3416(35)$ & $(17)$ \\
\hline
\end{tabular}

${ }^{*}$ Reductions in personnel: $<8 \%$ for none; $8-18 \%$ for minor; $>18 \%$ for major. Owing to missing data on occupation, the extent of downsizing was not determined for 28 participants.

years for each occupational group in each town. We derived the reduction in personnel from the employers' records covering all periods of full time employment, including date of start and, where appropriate, termination of work contract and Statistics Finland occupational titles. ${ }^{13}$ We calculated the percentage reduction in personnel by comparing person years worked in each occupational group for each town in 1993 with the corresponding person years in 1991 (272 categories of degree of downsizing). ${ }^{1}$ As in earlier studies, ${ }^{1-3}$ we classified the participants into the following groups: no downsizing (reductions in personnel $<8 \%$ ), minor downsizing (8-18\%), and major downsizing $(>18 \%)$

Outcomes were change in sickness absence between the periods before and after downsizing, all cause mortality, and cause specific mortality. We collected all sickness absences in 1991 (before downsizing) and from 1994 to 2000 (after downsizing) from town records listing all sickness absences for each employee. We noted only the rate of medically certified absences (number of spells divided by the person time in employment), a measure shown to be a more powerful predictor of mortality than several other established measures of health. ${ }^{14}$

We used participants' personal identification numbers (a unique number assigned to each Finnish citizen) to collect mortality data from the Statistics Finland register, which provides virtually complete population mortality data. We obtained the dates and causes of death for all participants who died between 1 July 1993 and 31 December 2000. In addition to deaths from cardiovascular diseases (international classification of diseases, 9th revision (ICD-9) codes 390-459; ICD-10 codes I00-I99), we analysed all cause mortality and deaths from smoking related cancer and alcohol related causes. ${ }^{15} 16$

We derived baseline characteristics from employers' records in 1991: sex, age group (18-45, 46-55, 56-65 years), socioeconomic status (higher grade non-manual, lower grade non-manual, manual workers), ${ }^{13}$ type of employment (permanent or temporary), and town.

\section{Statistical analysis}

For each employee, we calculated the number of spells of sickness absence divided by the length of employment for the periods before and after downsizing. To estimate the association between downsizing and change in sickness absence, we calculated mean differences in absence scores for permanent and temporary employees after minor and major downsizing compared with no downsizing. We adjusted mean differences and their $95 \%$ confidence intervals for baseline absence rate, as the magnitude of the change partly depends on the level at baseline. We also made adjustments for age, sex, socioeconomic status, and town.

To estimate relative mortality in people remaining at work after downsizing, we calculated the corresponding hazard ratios and $95 \%$ confidence intervals by Cox proportional hazard analyses. We studied the trend by treating downsizing as a continuous variable (no downsizing $=0$, minor downsizing $=1$, major downsizing $=2$ ). We made adjustments for age, sex, socioeconomic status, type of employment, and town. To study the short term and long term effects of downsizing on mortality, we split the follow up period after downsizing into two halves, using 1 January 1997 as a cut-off point. We entered an interaction term, time $\mathrm{X}$ downsizing, as a time dependent covariate into the non-proportional hazard model to calculate lagged hazards and their 95\% confidence intervals. We used the SAS 8.2 statistical package for all analyses.

\section{Results}

Table 1 shows the demographic characteristics of the participants by degree of downsizing. The study population was predominantly female and working in non-manual occupations. Major downsizing was more common in manual occupations, among women, and among temporary employees. Major downsizing was less common in Espoo than in other towns. Age was not associated with downsizing.

Table 2 presents differences in absence rates before and after downsizing by degree of downsizing. In permanent employees, but not in temporary employees, the increase in sickness absence was greater among employees who had experienced major downsizing than in those who had experienced no downsizing (P for interaction between type of employment and downsizing 0.04 ). The difference between the major downsizing group and the no downsizing group was 18 spells per 100 person years. We 
Table 2 Organisational downsizing and change in rate of medically certified sickness absence by type of employment

\begin{tabular}{|c|c|c|c|c|}
\hline \multirow[b]{2}{*}{ Extent of downsizing ${ }^{*}$} & \multicolumn{2}{|c|}{$\begin{array}{c}\text { Absence rate (spells per } 100 \text { person } \\
\text { years) }\end{array}$} & \multirow{2}{*}{\multicolumn{2}{|c|}{$\begin{array}{c}\text { Mean change (95\% } \\
\text { Cl) } \dagger\end{array}$}} \\
\hline & $\begin{array}{c}\text { Before } \\
\text { downsizing }\end{array}$ & After downsizing & & \\
\hline \multicolumn{5}{|c|}{ Permanent employment contract } \\
\hline None $(n=7102)$ & 53 & 70 & & 0 \\
\hline Minor $(n=9059)$ & 69 & 94 & 8 & (4 to 12$)$ \\
\hline Major $(n=4160)$ & 83 & 113 & 18 & (13 to 22) \\
\hline $\mathrm{P}$ for trend & & & \multicolumn{2}{|c|}{$<0.001$} \\
\hline \multicolumn{5}{|c|}{ Temporary employment contract } \\
\hline None $(n=813)$ & 51 & 66 & & 0 \\
\hline Minor $(n=641)$ & 59 & 77 & -5 & (-26 to 16$)$ \\
\hline Major $(\mathrm{n}=627)$ & 43 & 69 & 5 & $(-15$ to 25$)$ \\
\hline$P$ for trend & & & & 0.661 \\
\hline
\end{tabular}

${ }^{*}$ Reductions in personnel: $<8 \%$ for none; $8-18 \%$ for minor; $>18 \%$ for major.

†Adjusted for age, sex, socioeconomic status, and absence rate before downsizing.

found no sex differences ( $\mathrm{P}$ for interaction between sex and downsizing $\geq 0.40$ in permanent and temporary employees). Further adjustment for town had no effect on these results.

Table 3 shows the results for downsizing and mortality. A significant association occurred between downsizing and all cause mortality, which disappeared when we excluded deaths from cardiovascular diseases from all deaths. Employees who had experienced major downsizing had a twofold greater risk of death from cardiovascular diseases after adjustments. Further adjustment for town had little effect on these results (hazard ratio after major downsizing $1.9,95 \%$ confidence interval 1.0 to 3.8 ). We found no sex differences ( $\mathrm{P}$ for interaction 0.94 for all cause mortality and 0.22 for cardiovascular mortality). A stratified analysis of the 13837 employees with no absence before downsizing gave similar results (hazard ratio after major downsizing 2.6, 1.0 to 6.5 , $\mathrm{P}$ for trend 0.04 ). To study potential associations between downsizing and behavioural risk factors, we analysed mortality from smoking related cancer and alcohol related causes (data not shown). Major downsizing was not associated with death from these specific causes (adjusted hazard ratios 0.7 , 0.3 to 1.7 and $1.4,0.8$ to 2.5 ).

Finally, we analysed the short term and long term associations of downsizing on mortality (data not shown). Excess cardiovascular mortality was very pronounced in the first half of the follow up period after downsizing (adjusted hazard ratio 5.1, 1.4 to 19.3), but the risk was much less in the second half (1.4, 0.6 to 3.1). We found no evidence of a time dependent hazard for mortality from non-cardiovascular causes, smoking related cancer, and alcohol related causes,.

\section{Discussion}

This study showed an increased rate of medically certified sickness absence and increased risk of death after major downsizing among people who remain in work. Cardiovascular mortality was twice as high after major downsizing as after no downsizing. We found no evidence for associations between downsizing and mortality from other causes. The specific strengths of the study include a large sample size covering all municipal occupations, a long follow up period, and reliable data on employment, sickness absence, and mortality from national registers.

These results should be interpreted within the framework of work stress. We focused on municipal employees during a particularly important national recession, when the unemployment rate nearly tripled during a two year period and reached the rather substantial rate of $17 \%$. Municipalities were forced to downsize personnel to save costs, but the legislation did not allow parallel cuts in the services provided. This resulted in heightened levels of job demands and job insecurity, with a concomitant decrease in control among workers who remained in employment. ${ }^{23}$ Research on work stress indicates that such changes increase the likelihood of health problems, as indicated by rate of sickness absence ${ }^{317} 18$ and risk of cardiovascular morbidity and mortality. ${ }^{8-10} 19$

We found downsizing to be associated with increased sickness absence among permanent personnel but not among temporary employees. Employees with temporary contracts were the most likely to lose their jobs. For them, high job insecurity may increase the likelihood attending work while ill, ${ }^{5-7}$ a phenomenon known as sickness presenteeism. Morbidity among temporary employees may have increased after major downsizing without affecting absence rates owing to increased sickness presenteeism. In a Swedish study, working while ill was suggested as an explanation of the lower absence rates observed among women shortly after downsizing. ${ }^{5}$

\section{Potential explanations}

Identifying risk factors for cardiovascular mortality has special public health relevance. We found that the association between downsizing and cardiovascular death was strongest in the years immediately after reductions in personnel. We did not find corresponding results for other causes of death. The time dependent effect pattern and outcome specificity indicate a causal interpretation of the association between downsizing and cardiovascular mortality, rather than a confounded association. ${ }^{20}$ Downsizing may act as a trigger for fatal cardiovascular disease and a prognostic factor in people with pre-existing cardiovascular disease.

Two major criticisms of previous evidence on work stress and disease are that exposures and outcomes are often both substantively subjective and that analyses are not controlled for the confounding effect of material disadvantage. ${ }^{21}$ We feel that our study is able to surmount these criticisms. We used objective data to assess exposure and outcome, eliminating the problem of subjectivity. The study represents a natural experiment of the effects of a changing psychosocial work environment with no accompanying change in material conditions. We excluded from the cohort all people who left or lost their jobs during downsiz-

Table 3 Organisational downsizing and relative risk of death from all causes, cardiovascular diseases, and causes other than cardiovascular diseases

\begin{tabular}{|c|c|c|c|c|c|c|}
\hline \multirow[b]{2}{*}{ Extent of downsizing * } & \multicolumn{2}{|c|}{ All deaths $\dagger$} & \multicolumn{2}{|c|}{ Deaths due to cardiovascular diseases $†$} & \multicolumn{2}{|c|}{ Other deaths $\dagger$} \\
\hline & No of deaths & Hazard ratio $(95 \% \mathrm{Cl})$ & No of deaths & Hazard ratio $(95 \% \mathrm{Cl})$ & No of deaths & Hazard ratio $(95 \% \mathrm{Cl})$ \\
\hline None $(n=7915)$ & 100 & 1.00 & 18 & 1.00 & 82 & 1.00 \\
\hline Minor $(n=9700)$ & 164 & 1.21 (0.93 to 1.58$)$ & 40 & 1.50 (0.83 to 2.69$)$ & 124 & $1.15(0.85$ to 1.55$)$ \\
\hline Major $(n=4787)$ & 83 & $1.37(1.00$ to 1.87$)$ & 21 & 2.00 (1.02 to 3.92$)$ & 62 & 1.24 (0.87 to 1.76$)$ \\
\hline $\mathrm{P}$ for trend & & 0.047 & & 0.043 & & 0.231 \\
\hline
\end{tabular}

${ }^{*}$ Reductions in personnel: $<8 \%$ for none; $8-18 \%$ for minor; $>18 \%$ for major. Permanent and temporary employees combined owing to small number of deaths in temporary group ( $\mathrm{n}=18$ ). † Hazard ratios and $95 \%$ confidence intervals are adjusted for age in 10 year categories, sex, socioeconomic status, and of type of employment. 
ing. During the downsizing, only $7.5 \%$ of the participants changed their occupation, of whom less than 1\% moved from non-manual to manual occupations. Thus, only a very small minority were exposed to increased material disadvantage, making a change in material circumstances an unlikely explanation of our findings.

Selection is a common source of confounding in observational studies. For example, if people who left their jobs during major downsizing had lower cardiovascular mortality than those who worked in groups where there was little downsizing, then selective retention of people at higher cardiovascular risk would explain the association between downsizing and cardiovascular mortality. Such confounding is unlikely in this study, because the risk of cardiovascular death among the leavers was higher than that among those who kept their jobs.

Major downsizing was more common among employees in the lowest socioeconomic group than among those in the highest socioeconomic group, another important potential source of selection bias. However, the association between downsizing and cardiovascular mortality remained after adjustment for socioeconomic status. Downsizing was not associated with deaths from smoking related cancer and alcohol related causes (other causes of mortality with well documented socioeconomic gradients). Furthermore, socioeconomic status, early living conditions, chemical hazards at work, and behavioural health risks are relatively stable predictors of health that are likely to produce permanent differences in mortality, not the temporary differences observed in this study.

The participants were clustered within towns, and thus area characteristics could confound any association between downsizing and mortality. ${ }^{22}$ Towns in deprived regions might be forced to downsize to a greater extent, and deprivation could explain the increased mortality. For example, the unemployment rate varied between the towns, being highest in Turku (21\%) and lowest in Espoo (14\%) during the downsizing. However, adjustment of the analyses for town had little effect on the results, making confounding by regional characteristics an unlikely explanation of our findings.

\section{Limitations}

The associations observed in this study between downsizing, sickness absence, and cardiovascular mortality may represent an underestimate rather than an overestimate of the actual effect of downsizing. Exit from the labour market partly depends on health. ${ }^{23}$ In our study, employees with health problems were more likely to lose their job during the downsizing. After adjustment for age, sex, socioeconomic status, and type of employment, they had a higher absence rate before downsizing (relative risk 1.4, 95\% confidence interval 1.4 to 1.5 ) and higher mortality from all causes and from cardiovascular diseases (hazard ratios $1.5,1.2$ to 1.9 and $1.6,1.0$ to 2.5$)$. The remaining employees, the focus of this study, had relatively good health; they were employed, relatively young, and predominantly female, all determinants of a low risk target population for studying cardiovascular mortality.

None the less, with only 79 cardiovascular deaths, we acknowledge that the findings of our study should be validated in further studies with larger samples. Such replication would also help to determine the generalisability of the findings, whether they apply to both sexes, and whether differences between societies and sectors of work moderate the effects of downsizing on health. Our analyses treated individual workers as independent. Future studies that can identify work groups and adjust for clustering are likely to strengthen the findings presented here.

\section{What is already known on this topic}

In the global economy, downsizing seems to be an increasingly important trend in industrialised countries

The association between downsizing and sickness absence has been shown, but whether this association varies by employment contract is unknown

The association between downsizing and mortality has remained unknown

\section{What this study adds}

Organisational downsizing seems to be associated with increased levels of sickness absence and an increased risk of death from cardiovascular disease in employees who keep their jobs

Policy makers, employers, and occupational health professionals should recognise that severe health risks may be associated with organisational downsizing

\section{Conclusions}

As expectations of continuing growth have evaporated in industrialised countries with the advent of the global economy, downsizing has become an increasingly important trend. This study indicates that downsizing may lead to elevated absence rates and increase cardiovascular mortality among people who remain employees. Policy makers, employers, and occupational health professionals should recognise that downsizing may pose a severe risk to health.

Contributors: JV, the principal investigator and the director of the 10-town study, designed and conducted the study together with MK. JV did all the analyses, and MK had the main responsibility for writing the paper. JV will act as guarantor. JP constructed the downsizing measure and supervised data analyses. AL, MV, PV, and JEF helped in designing the study, interpreting the results, and writing the paper.

Funding: This study was supported by the Academy of Finland (projects 77560, 104891, and 105195), the Finnish Work Environment Foundation (project 101190), and the participating towns. MK also works at the Department of Psychology, University of Helsinki, Finland. JEF is supported by the Medical Research Council (grant number 47413).

Competing interests: None declared.

Ethical approval: The ethics committee of the Finnish Institute of Occupational Health approved the study.

1 Vahtera J, Kivimäki M, Pentti J. Effect of organisational downsizing on health of employees. Lancet 1997;350:1124-8.

2 Kivimäki M, Vahtera J, Pentti J, Thomson L, Griffiths A, Cox T. Downsizing, changes in work, and self-rated health of employees: a 7-year 3-wave panel study. Anxiety, Stress and Coping 2001;14:59-73.

3 Kivimäki M, Vahtera J, Pentti J, Ferrie JE. Factors underlying the effect of organisational downsizing on health of employees: longitudinal cohort study. $B M J$ 2000;320:971-5.

Quinlan M Mayhew $\mathrm{C}$ Bohle P.The global expansion of precarious employment, work Quinlan $M$, Mayhew $\mathrm{C}$, Bohle P. The global expansion of precarious employment, work disorganization, and consequences for occupational health: a review of recent research.

5 Theorell T, Oxenstierna G, Ferrie J, Hagberg J, Alfredsson L. Downsizing of staff is associated with lowered medically certified sick leave in female employees. Occup Environ Med 2003;60:e9.

6 Aronsson G, Gustafsson K, Dallner M. Sick but yet at work: an empirical study of sickness presenteeism. J Epidemiol Community Health 2000;54:502-9.

7 Virtanen M, Kivimäki M, Elovainio M, Vahtera J, Ferrie JE. From insecure to secure employment: changes in work, health, health related behaviours, and sickness absence. Occup Environ Med 2003;60:948-53.

8 Bosma H, Peter R, Siegrist J, Marmot M. Two alternative job stress models and the risk of coronary heart disease. Am J Public Health 1998;88:68-74.

9 Hemingway H, Marmot M. Psychosocial factors in the aetiology and prognosis of coronary heart disease: systematic review of prospective cohort studies. BMJ 1999;318:1460-7.

10 Kivimäki M, Leino-Arjas P, Luukkonen R, Riihimäki H, Vahtera J, Kirjonen J. Work stress and risk of cardiovascular mortality: prospective cohort study of industrial employees. BMJ 2002;325:857-61. 
11 Martikainen P, Valkonen T. Mortality after the death of a spouse: rates and causes of death in a large Finnish cohort. Am J Public Health 1996;86:1087-93.

12 Lichtenstein P, Gatz M, Berg S. A twin study of mortality after spousal bereavement. Psychol Med 1998;28:635-43.

13 Classification of occupations: handbook no 14. Helsinki: Statistics Finland, 1987.

14 Kivimäki M, Head J, Ferrie JE, Shipley M, Vahtera J, Marmot MG. Sickness absence as a global measure of health: evidence from mortality in the Whitehall II prospective cohort study. BMJ 2003;327:364-8.

15 Davey Smith G, Shipley M, Leon DA. Height and mortality from cancer among men: prospective observational study. BMJ 1998;317:1351-2.

16 Hart CL, Smith GD, Hole DJ, Hawthorne VM. Alcohol consumption and mortality from all causes, coronary heart disease, and stroke: results from a prospective cohort from all causes, coronary heart disease, and stroke: results from a pros
study of Scottish men with 21 years of follow up. BMJ 1999;318:1725-9.

17 North F, Syme SL, Feeney A, Head J, Shipley MJ, Marmot MG. Explaining socioeconomic differences in sickness absence: the Whitehall II study. BMJ 1993:306:361-6.

18 Melchior M, Niedhammer I, Berkman LF Goldberg M. Do psychosocial work factors and social relations exert independent effects on sickness absence? A six year prospective study of the GAZEL cohort. J Epidemiol Community Health 2003;57:285-93.

19 Everson SA, Lynch JW, Chesney MA, Kaplan GA, Goldberg DE, Shade SB, et al. Interaction of workplace demands and cardiovascular reactivity in progression of carotid atherosclerosis: population based study. BMJ 1997;314:553-8.

20 Weiss NS. Can the specificity of an association be rehabilitated as a basis for supporting a causal hypothesis? Epidemiology 2002;13:6-8

21 McLeod J, Davey Smith G, Heslop P, Metcalfe C, Carroll D, Hart C. Psychological stress and cardiovascular disease: empirical demonstration of bias in a prospective observational study of Scottish men. BMJ 2002;324:1247-51.
22 Lynch JW, Kaplan GA, Pamuk ER, Cohen RD, Heck KE, Balfour JL, et al. Income inequality and mortality in metropolitan areas of the United States. Am J Public Health 1998;88:1074-80.

23 Ferrie JE. Labour market status, insecurity and health. J Health Psychol 1997;2:373-97.

(Accepted 27 November 2003)

doi 10.1136/bmj.37972.496262.0D

Finnish Institute of Occupational Health, Topeliuksenkatu 41 aA, FIN-00250 Helsinki, Finland

Jussi Vahtera senior researcher

Mika Kivimäki professor

Jaana Pentti statistician

Anne Linna research fellow

Marianna Virtanen research fellow

University of Tampere, Medical School, FIN-33014 University of Tampere, Finland Pekka Virtanen senior lecturer

International Centre for Health and Society, Department of Epidemiology and Public Health, University College London Medical School, London WC1E 6BT Jane E Ferrie senior research fellow

Correspondence to: J Vahtera, Finnish Institute of Occupational Health, Hämeenkatu 10, FIN-20500 Turku, Finland jussi.vahtera@ttl.fi 